\title{
Multidisciplinary Pain Treatment Center
}

National Cancer Institute

\section{Source}

National Cancer Institute. Multidisciplinary Pain Treatment Center. NCI Thesaurus. Code C21071.

Free-standing or institution-based clinics devoted to pain management from a multidisciplinary perspective. Team members usually include physicians, nurses, social workers, physical therapists, occupational therapists, respiratory therapists, pharmacists, and the patient's family and friends, who approach the patient's needs as a team. 